Revista de Derecho

\title{
El concepto de matrimonio y la Opinión Consultiva 24/17. Una crítica
}

The concept of marriage and the Advisory Opinion. A critic

Vicente Manuel Solano Paucay

Universidad de Cuenca, Ecuador

vicente.solano@ucuenca.edu.ec

ORCID: 0000-0003-3955-81

DOI: https://doi.org/10.32719/26312484.2019.32.5

Fecha de recepción: 19 de enero de 2019

Fecha de aceptación: 9 de septiembre de 2019 


\section{RESUMEN}

El artículo explora las críticas que se han formulado sobre el concepto de matrimonio que contiene la Opinión Consultiva 24/17. Desde una posición conservadora se señala que el matrimonio se circunscribe a personas de diferente sexo. La premisa que sostiene el pro-matrimonio "heterosexual" establece la unión entre hombre y mujer, por lo que única y exclusivamente el vínculo matrimonial se podría constituir con personas de diferente sexo. La tesis central sobre el matrimonio se concentra en que este, desde sus orígenes, su concepto o naturaleza, ha sido exclusivo de las personas heterosexuales. Y esta noción se fundamentaría en base al artículo 67 de la Constitución ecuatoriana. Mientras, desde una posición más progresista, se rechaza que el concepto sea tan reducido. El movimiento promatrimonio igualitario sustenta su razonamiento sobre el principio de igualdad, pero, de manera específica, en la prohibición de discriminación que se encuentra en el inciso segundo del mismo artículo 11 número 2. Por ello, analizo y critico la primera y segunda posición, desde una perspectiva interpretativa y moral, con el fin de obtener una mejor argumentación, desde un minucioso análisis conceptual. Así desde la tesis interpretativa la regla del artículo 67 podría ser vista en cuatro posibles "interpretaciones" -normas- plausibles del matrimonio. Por otro lado, bajo la tesis moral utilizaré el argumento moral ingenuo y el sofisticado con el objetivo de realizar una redefinición de los argumentos morales en cuanto al matrimonio.

Palabras Clave: Corte Interamericana de Derechos Humanos, función consultiva, matrimonio igualitario, género, moral.

\section{ABSTRACT}

The article explores the criticisms that have been made about the concept of marriage contained in Advisory Opinion 24/17. From a conservative position it is indicated that the marriage is limited to people of different sex. The premise that supports the "heterosexual" pro-marriage establishes the union between man and woman, for that reason only and exclusively the marriage bond could be constituted with people of different sex. The central thesis about marriage focuses on the fact that, from its origins, its concept or nature, it has been exclusive to heterosexual people. Also, this notion would be based on article 67 of the Ecuadorian Constitution. While from a more progressive position it is rejected that the concept is so reduced. Meanwhile, the egalitarian pro-marriage movement supports its reasoning on the principle of equality, but specifically, in the prohibition of discrimination found in the second clause of the same article 11 numeral 2. Therefore, I analyze and criticize the first and second position, from an interpretative and moral perspective, in order to obtain a good argumentation, from a meticulous conceptual analysis. The interpretative thesis the rule of article 67 could be seen in four possible "interpretations" - plausible rules of marriage. On the other 
hand, under the moral thesis I will use the naive and sophisticated moral argument with the aim of realizing a redefinition of moral arguments regarding marriage. KeYwords: Inter-American Court of Human Rights, advisory function, equal marriage, gender, moral.

\section{INTRODUCCIÓN}

$\mathrm{L}$

a Constitución ecuatoriana de 2008 elevó a rango constitucional la institución del

matrimonio. Así, el movimiento pro-matrimonio "heterosexual" se ha centrado en el argumento de la tesis de la interpretación literal de la Constitución. Mientras tanto el movimiento pro-matrimonio "igualitario" defiende la necesidad de abandonar la tesis literalista. El movimiento pro-matrimonio "heterosexual" ha fundado su tesis en el artículo 67 de la Constitución que en lo principal señala que: "El matrimonio es la unión entre hombre y mujer". Esto implicaría que nuestro texto constitucional permitiría únicamente el matrimonio para las personas de diferente sexo.

En este contexto, el 9 de enero de 2018 la Corte Interamericana de Derechos Humanos (Corte IDH en adelante) hizo pública su opinión consultiva 24/17 sobre identidad de género, igualdad y no discriminación a parejas del mismo sexo. ${ }^{1}$ En lo principal, esta reconoció la identidad de género como un derecho autónomo, así como la protección de la Convención Americana de las parejas del mismo sexo y la garantía del matrimonio sin importar la orientación sexual. En la que es considerada una de las más importantes opiniones consultivas, esta expande el concepto de matrimonio con el fin de garantizar que a esta institución puedan acceder las personas de diferente sexo. La opinión consultiva ha generado un gran debate sobre la aplicación de esta en el ordenamiento jurídico ecuatoriano. No obstante, este artículo no pretende determinar la obligatoriedad o vinculatoriedad de esta, sino hacer un examen exhaustivo de las tesis que sostienen la pretensión a favor o en contra del matrimonio igualitario.

En cuanto a la teoría de la interpretación jurídica pretendo trabajar desde algunas premisas que son primordiales, en primer lugar, asumo una concepción escéptica realista, no así formalista o neo-cognitivista. La teoría formalista acepta que la interpretación es un acto de conocimiento, es decir, que se busca descubrir el único significado verdadero de un texto normativo; por tanto, pertenece al discurso descriptivo. En

1. Opinión Consultiva 24/17 (Corte Interamericana de Derechos Humanos, 24 de noviembre de 2017). 
cambio, la teoría neo-cognitivista -hegemónica- asume que existe una vaguedad de los textos normativos, en síntesis, que, frente a los casos fáciles, en los que el campo de aplicación es claro, también existen los llamados casos difíciles, donde el juez, puede de forma discrecional definir la interpretación en cuanto a los hechos, es decir, en la interpretación en concreto, no así lo mismo de la interpretación en abstracto. Por tanto, excluye que los métodos de interpretación o la misma discrecionalidad judicial puedan operar en abstracto.

Finalmente, la teoría del escepticismo realista sostiene que tanto los diversos métodos de interpretación y la dogmática son elementos que determina la equivocidad y la vaguedad del lenguaje de las fuentes del derecho, lo que implica que efectivamente un texto normativo tiene varios significados, es decir, no hay un sentido objetivo o univoco como señalan los formalistas. Es decir, los enunciados interpretativos pertenecen al discurso prescriptivo, mas no al descriptivo; por tanto, son carentes de valor de verdad. Tanto así que la atribución de significado a un texto normativo no puede ser valorado en el sentido de correcto o incorrecto, sino que los jueces de las altas cortes son los que determinan el sentido último de los mismos. ${ }^{2}$ Entonces, admito que, sobre las controversias en torno al estatuto lógico de la interpretación jurídica judicial, presupongo que no es un acto de conocimiento sino un acto de voluntad.

Sobre la tesis moral, me centraré en la teoría de la justicia como comunidad y vida buena que sobre todo ha desarrollado Michael Sandel, que critica el liberalismo deontológico por carecer de la posibilidad de ayudar a elegir principios de justicia o una concepción de lo bueno. Deviniendo en la necesidad de una cohesión comunitaria que permita dar respuesta a problemas que han puesto en entredicho las alternativas ofrecidas por las democracias denominadas liberales. Es así como el comunitarismo desde una perspectiva aristotélica permite configurar las mejores razones o los fines que permiten la regulación de las condiciones de admisión y exclusión del matrimonio y la familia. Concluyendo esa línea argumentativa, haré una reflexión desde el principio de igualdad y no discriminación en cuanto a la diversidad sexual y cómo este permite alcanzar un mayor bienestar para los ciudadanos en una sociedad de derechos.

\section{EL MATRIMONIO Y SUS DOS TESIS}

La tesis que sostiene el argumento del movimiento pro-matrimonio "heterosexual" está centrada en que por naturaleza se establece la unión entre hombre y mujer. Es decir, que única y exclusivamente el vínculo matrimonial se podría constituir con

2. Ricardo Guastini, La teoría e ideología de la interpretación constitucional (Madrid: Trotta, 2008), 39-42. 
personas de diferente sexo. En este sentido la tesis central sobre el matrimonio se concentra en que el matrimonio, desde sus orígenes, su concepto o naturaleza, ha sido exclusivo de las personas heterosexuales. Además, esta tesis se erige jurídicamente con base en el artículo 67 de la Constitución que en su capítulo sobre los derechos de libertad señala lo siguiente:

Se reconoce la familia en sus diversos tipos. El Estado la protegerá como núcleo fundamental de la sociedad y garantizará condiciones que favorezcan integralmente la consecución de sus fines. Estas se constituirán por vínculos jurídicos o de hecho y se basarán en la igualdad de derechos y oportunidades de sus integrantes. El matrimonio es la unión entre hombre y mujer, se fundará en el libre consentimiento de las personas contrayentes y en la igualdad de sus derechos, obligaciones y capacidad legal.

No obstante, el movimiento pro-matrimonio igualitario sustenta su argumento sobre el principio de igualdad, jurídicamente defienden su posición en base a este principio, pero de manera específica, en la prohibición de discriminación que se encuentra en el inciso segundo del mismo artículo 11 numeral 2, cuando dispone:

Art. 11.2. (...) Nadie podrá ser discriminado por razones de etnia, lugar de nacimiento, edad, sexo, identidad de género, identidad cultural, estado civil, idioma, religión, ideología, filiación política, pasado judicial, condición socio-económica, condición migratoria, orientación sexual, estado de salud, portar VIH, discapacidad, diferencia física; ni por cualquier otra distinción, personal o colectiva, temporal o permanente, que tenga por objeto o resultado menoscabar o anular el reconocimiento, goce o ejercicio de los derechos. La ley sancionará toda forma de discriminación.

Con estas observaciones, la pretensión de este trabajo será denotar que las pretendidas objeciones del matrimonio, sea el igualitario o el heterosexual, pueden ser reconstruidas a partir de una tesis interpretativa y moral, que nos permita llevar a cabo un análisis que termine por mejorar la cuestión argumentativa en cuanto al problema conceptual del matrimonio. 


\section{LA TESIS INTERPRETATIVA}

\section{La regla del artículo 67 podría ser vista en cuatro posibles "interpretaciones"3}

3. Cualquier interpretación (norma) del texto constitucional, debe ajustarse a las reglas de interpretación constitucional que la propia Constitución determina en los artículos 427 y 11. La primera disposición normativa señala: Art. 427.- Las normas constitucionales se interpretarán por el tenor literal que más se ajuste a la Constitución en su integralidad. En caso de duda, se interpretarán en el sentido que más favorezca a la plena vigencia de los derechos y que mejor respete la voluntad del constituyente, y de acuerdo con los principios generales de la interpretación constitucional. La segunda disposición señala: Art. 11.- El ejercicio de los derechos se regirá por los siguientes principios:

1. Los derechos se podrán ejercer, promover y exigir de forma individual o colectiva ante las autoridades competentes; estas autoridades garantizarán su cumplimiento. 2. Todas las personas son iguales y gozarán de los mismos derechos, deberes y oportunidades. Nadie podrá ser discriminado por razones de etnia, lugar de nacimiento, edad, sexo, identidad de género, identidad cultural, estado civil, idioma, religión, ideología, filiación política, pasado judicial, condición socioeconómica, condición migratoria, orientación sexual, estado de salud, portar VIH, discapacidad, diferencia física; ni por cualquier otra distinción, personal o colectiva, temporal o permanente, que tenga por objeto o resultado menoscabar o anular el reconocimiento, goce o ejercicio de los derechos. La ley sancionará toda forma de discriminación. El Estado adoptará medidas de acción afirmativa que promuevan la igualdad real en favor de los titulares de derechos que se encuentren en situación de desigualdad. 3. Los derechos y garantías establecidos en la Constitución y en los instrumentos internacionales de derechos humanos serán de directa e inmediata aplicación por y ante cualquier servidora o servidor público, administrativo o judicial, de oficio o a petición de parte. Para el ejercicio de los derechos y las garantías constitucionales no se exigirán condiciones o requisitos que no estén establecidos en la Constitución o la ley. Los derechos serán plenamente justiciables. No podrá alegarse falta de norma jurídica para justificar su violación o desconocimiento, para desechar la acción por esos hechos ni para negar su reconocimiento. 4. Ninguna norma jurídica podrá restringir el contenido de los derechos ni de las garantías constitucionales. 5. En materia de derechos y garantías constitucionales, las servidoras y servidores públicos, administrativos o judiciales, deberán aplicar la norma y la interpretación que más favorezcan su efectiva vigencia. 6. Todos los principios y los derechos son inalienables, irrenunciables, indivisibles, interdependientes y de igual jerarquía. 7. El reconocimiento de los derechos y garantías establecidos en la Constitución y en los instrumentos internacionales de derechos humanos, no excluirá los demás derechos derivados de la dignidad de las personas, comunidades, pueblos y nacionalidades, que sean necesarios para su pleno desenvolvimiento. 8. El contenido de los derechos se desarrollará de manera progresiva a través de las normas, la jurisprudencia y las políticas públicas. El Estado generará y garantizará las condiciones necesarias para su pleno reconocimiento y ejercicio. Será inconstitucional cualquier acción u omisión de carácter regresivo que disminuya, menoscabe o anule injustificadamente el ejercicio de los derechos. 9. El más alto deber del Estado consiste en respetar y hacer respetar los derechos garantizados en la Constitución. El Estado, sus delegatarios, concesionarios y toda persona que actúe en ejercicio de una potestad pública, estarán obligados a reparar las violaciones a los derechos de los particulares por la falta o deficiencia en la prestación de los servicios públicos, o por las acciones u omisiones de sus funcionarias y funcionarios, y empleadas y empleados públicos en el desempeño de sus cargos. El Estado ejercerá de forma inmediata el derecho de repetición en contra de las personas responsables del daño producido, sin perjuicio de las responsabilidades civiles, penales y administrativas. El Estado será responsable por detención arbitraria, error judicial, retardo injustificado o inadecuada administración de justicia, violación del derecho a la tutela judicial efectiva, y por las violaciones de los principios y reglas del debido proceso. Cuando una sentencia condenatoria sea reformada o revocada, el Estado reparará a 
-normas $-^{4}$ plausibles del matrimonio. La primera estaría en que el texto explícitamente prohibiría el vínculo matrimonial que no sea entre un hombre y una mujer. La segunda es que la disposición constitucional sería una norma constitutiva del matrimonio entendido únicamente como "una unión entre un hombre y una mujer". Esto nos llevaría a sostener

que este es exclusivo de las personas heterosexuales. Una tercera estaría en sostener que hay una contradicción entre disposiciones constitucionales, entre el 11 numeral 2 (principio) y el 67 (regla). Una cuarta indicaría que haciendo uso de una interpretación literalsistemática esta contradicción anterior seria inexistente.

La primera interpretación se basaría en el método de interpretación literal del artículo 67 que sostendría que está prohibido el matrimonio entre personas del mismo sexo, no obstante, parece posible que esta norma-regla no opera con un operador deóntico ${ }^{5}$ que, de forma explícita, prohíba el vínculo matrimonial entre personas del mismo sexo. En este sentido, al no existir un operador deóntico prohibitivo (en adelante Php), se definiría que no existe en todo el texto constitucional una disposición prohibitiva del matrimonio igualitario. Por tanto, esta norma no estaría contemplada en el margen de interpretación posible.

En una segunda interpretación se establece que la norma-regla del art. 67 se configura como una norma constitutiva, ${ }^{6}$ es decir, según Guastini, estamos frente a una norma que no prescribe nada a nadie, que no crea un efecto jurídico. En este caso estamos frente al tipo de norma constitutiva que, aunque tiene una estructura condicional (Si P, entonces q), no tiene una expresión deóntica en el consecuente. Por ejemplo, cuando se señala que "los mayores de dieciocho años son mayores de edad". ${ }^{7}$ Esa misma estructura es la que tendría la norma que examinamos, por tanto, si, y solo si, la unión es entre un hombre y una mujer, se podría establecer la existencia de vínculo matrimonial. Esto implica que exclusivamente el matrimonio es entre personas heterosexuales, excluyendo a quienes no lo son.

Una tercera interpretación implicaría que existe una contradicción en la Constitución entre los artículos 67 y 11 número 2. Es decir, dos disposiciones jurídicas son

la persona que haya sufrido pena como resultado de tal sentencia y, declarada la responsabilidad por tales actos de servidoras o servidores públicos, administrativos o judiciales, se repetirá en contra de ellos.

4. Vicente Solano, "Controversias interpretativas sobre la regulación en la Constitución ecuatoriana de la interpretación constitucional", en Vicente Solano y Marcelo Aguilera, Hitos de la Constitución Ecuatoriana (Cuenca: EDUNICA, 2018), 43-60.

5. Los operadores deónticos son: $(\mathrm{Ph})=$ Prohibido, $(\mathrm{Ob})=$ Obligatorio, $(\mathrm{P})=$ Permitido.

6. Riccardo Guastini, La sintaxis del derecho (Madrid: Marcial Pons, 2016), 60.

7. Ibíd. 
contradictorias cuando en iguales circunstancias una prohíbe y otra permite a un sujeto la misma conducta, en condiciones iguales de espacio y tiempo. Por un lado, el artículo 67 y 11 número 2 aparentemente son contradictorias la una con la otra, dado que refieren a hechos similares: la permisión de contraer matrimonio a personas de diferente sexo y la prohibición de discriminar por orientación sexual. Esto se podría expresar lógicamente de la siguiente forma:

1. $(\mathrm{Px})^{8}$

2. $(\text { Phy })^{9}$

En este caso x representa la conducta "contraer matrimonio" mientras y la conducta "discriminar", por ende, no estamos frente a una misma conducta, sino tenemos dos, por tanto, no habría una contradicción. Otra cosa sería que exista una norma que permita y a su vez prohíba el matrimonio. Esta se podría expresar de la siguiente forma:

$$
(\mathrm{Py})^{\wedge}(\sim \mathrm{Py})
$$

En síntesis, de lo que se puede colegir del texto constitucional es que no existe una posible contradicción. La contradicción solo podría existir si, y solo si, de la interpretación del artículo 67, se estableciera la prohibición de contraer matrimonio entre personas del mismo sexo y la prohibición de discriminar del articulo 11 número 2, lo cual ha sido desvirtuado.

En la cuarta interpretación se utilizarán los métodos literal y sistemático de la Constitución, por ello, para empezar, debemos contar con lo que se señala en el articulo que afirma "se reconoce la familia en sus diversos tipos", a lo que se agrega la obligación de protección que el Estado debe asegurar. Asimismo, reconoce a la familia en sus diversos tipos, y reconoce los derechos que de ella derivan a todos sus miembros y la obligación del Estado de protegerla. A continuación, se encuentra la formulación normativa sobre al matrimonio, en consecuencia, este concepto no puede ser entendido de manera apartada de la noción de familia.

En este sentido, debemos mencionar que, como señala Ramiro Ávila, existen principios de aplicación de los derechos, ${ }^{10}$ como el principio de igualdad y la prohibición de discriminación que se encuentra en el art. 11 número 2; por consiguiente, a partir de este principio el Estado reconoce y se compromete asegurar a todas las personas los

8. Permitido contraer matrimonio entre un hombre y una mujer.

9. Prohibido discriminar por razones de orientación sexual.

10. Ramiro Ávila, Los derechos y sus garantías: ensayos críticos (Quito: Corte Constitucional para el Período de Transición / CEDEC, 2012), 66. 
mismos derechos contenidos en la Constitución. Recordemos que, como señala Ávila, este principio de aplicación sirve para desarrollar los principios sustantivos (derechos) como los de libertad, donde se encuentra situada la disposición constitucional del matrimonio. Más adelante, en esta formulación normativa, se prohíbe explícitamente que alguien pueda ser discriminado por razones de orientación sexual cuando estas tengan como objeto o resultado menoscabar o anular el reconocimiento, goce o ejercicio de los derechos. E incluso establece que la ley deberá sancionar cualquier forma de discriminación. En este caso, se podría expresar que la prohibición de discriminación está condicionada al menoscabo o anulación del reconocimiento o ejercicio de un derecho. Esta formulación se podría expresar de la siguiente forma:

$$
(\mathrm{Php} \leftrightarrow \mathrm{q})^{11}
$$

En consecuencia, la Constitución ecuatoriana establece una prohibición de discriminación en el reconocimiento y ejercicio de un derecho, y, en tanto se reconoce el matrimonio y las familias en sus diversos tipos como un ejercicio del derecho a la libertad, cualquier tipo de restricción de este derecho para parejas del mismo sexo estaría constitucionalmente prohibida. No obstante, estas cuatro posibles formas de interpretar las disposiciones normativas que se refieren al matrimonio y la prohibición de discriminación no pretenden ser exhaustivas, sino que intentan demostrar la fragilidad de la atribución de significado que tendrían las mismas. Ante esta "textura abierta del derecho", ${ }^{12}$ entra en escena la discrecionalidad judicial que tendrá que finalmente determinar una interpretación que esté orientada a respetar los principios de aplicación, como el principio pro-persona, o el de favorabilidad de los derechos.

\section{LA TESIS MORAL}

Para esta parte utilizaré el argumento moral ingenuo y el sofisticado que, según Michael Sandel, en el primer caso consiste en que "se propugna que la justicia de las leyes depende del valor moral de la conducta que prohíben o amparan". ${ }^{13}$ En el segundo caso, "se sostiene que la justicia de esas leyes no depende de un juicio moral sustantivo sobre la conducta en cuestión, sino de una teoría más general acerca de la prioridad relativa entre el principio de la mayoría y los derechos individuales, o lo

11. Prohibido discriminar ( $\rho$ ) si y solo si, la misma tiene como objeto o resultado el menoscabo del ejercicio de un derecho (q).

12. Herbert L. Hart, El concepto del Derecho (Buenos Aires: Abeledo Perrot, 2008), 159.

13. Michael Sandel, Filosofia pública. Ensayos sobre moral en política (Barcelona: Marbot, 2008), 145. 
que es lo mismo, entre la democracia y la libertad", ${ }^{14}$ con el objetivo de realizar una redefinición de las tesis morales en cuanto al matrimonio.

En este sentido, el argumento moral sofisticado sostendría que desde la noción de libertad -voluntarista- cualquier individuo debería tener la opción de escoger de forma libre si quieren o no acceder al matrimonio, sea homosexual o heterosexual, siempre y cuando no hagan daño a los demás, dejando de lado su valoración. En este sentido argumenta que debates como el del matrimonio igualitario y el del derecho al aborto no pueden resolverse simplemente sosteniendo, como lo hacen algunos liberales, que el Estado debe ser moralmente neutro, y que por tanto no debe entrar ni a juzgar la calidad moral de las relaciones homosexuales, ni a inmiscuirse en la libertad de elección de las mujeres.

Ante la debilidad de la tesis interpretativa y la aplicación de las disposiciones jurídicas sobre el matrimonio, ahora presentaré algunas observaciones sobre este concepto. El movimiento pro-matrimonio heterosexual sostiene que el matrimonio no puede ser para personas del mismo sexo por cuanto tiene como finalidad la procreación.

\section{El ARgumento de la PROCReACión}

Un argumento que defiende el pro-matrimonio heterosexual se erige en cuanto a las finalidades del matrimonio; así, el artículo 81 del Código Civil señala que este es un "contrato solemne por el cual un hombre y una mujer se unen con el fin de vivir juntos, procrear y auxiliarse mutuamente". ${ }^{15}$ Sin embargo, fuera de la prescripción normativa de carácter infra constitucional, esta tesis es defendida como una fundamental, para defender la idea de que el matrimonio debe ser una institución jurídica exclusiva de las personas de diferente sexo. Así, el argumento podría ser:

1. Las personas de diferente sexo pueden procrear.

2. Sin finalidades no existe matrimonio.

3. Procrear es una finalidad del matrimonio.

4. Sin procrear no hay matrimonio.

En este sentido, la discusión se centra en que quienes defienden la noción de matrimonio exclusiva a personas de diferente sexo excluyen que a la misma no se puede acceder si no es con el fin de la procreación. En tanto que las personas del mismo sexo ya estarían reconocidas bajo la unión de hecho, como en el caso francés con el PACS

14. Ibíd.

15. Ecuador, Código Civil, Registro Oficial 46, 24 de junio de 2015 (el énfasis es nuestro). 
(Pacto Civil de Solidaridad), entendido como un "contrato de organización de la vida común entre dos personas mayores de sexo diferente o de mismo sexo", ${ }^{16}$ pero que no tiene los mismos derechos y obligaciones que el vínculo matrimonial. Por tanto, el PACS es aceptado en el conjunto de la sociedad, ya que no contribuye a la procreación.

Entonces, la discusión se centraría en si procrear es o no un elemento definitorio del matrimonio. Por un lado, si procrear es un elemento definitorio y que implica la existencia o nulidad de esta institución jurídica, ¿qué sucede cuando una persona no puede consumar al acto conyugal? ¿O si bajo el consentimiento mutuo de la pareja deciden efectivamente no tener hijos?

Bajo el análisis normativo del primer caso, se podría considerar como en el caso chileno -símil al ecuatoriano- que "la imposibilidad absoluta de consumar el matrimonio mediante la cópula sexual puede conducir a afirmar, si ya no la nulidad del matrimonio, la inexistencia del mismo". ${ }^{17}$ En consecuencia, quien tenga impotencia perpetua e incurable no podría acceder al matrimonio. El segundo caso cada vez es más común entre quienes deciden contraer matrimonio; el debate se concentra en si, a más de ser pareja, se quiera o no tener descendencia. En varios casos, ya no aislados, deciden que su ideal de trascendencia no está prefijado en únicamente tener hijos sino en otras formas que implican su desarrollo profesional, académico, u otras. Por ende, estas personas tampoco podrían acceder al matrimonio por cuanto en su tipo ideal no estaría la procreación como una finalidad. Bajo el examen normativo, como ya hemos indicado, estaríamos concluyendo que no existía el matrimonio. En ambos casos, entonces bajo la imposibilidad moral y jurídica, estaríamos frente a la inexistencia de esta institución. Algo que a claras luces no solamente es carente de racionalidad.

La procreación en sí tiene vínculos con el matrimonio, en primer lugar, como la idea católica "heredada de San Agustín, del matrimonio como el único lugar legítimo para la sexualidad orientada a la reproducción". ${ }^{18}$ En segundo lugar, su vínculo sería el histórico y jurídico, que implicaría que, a pesar de que la regulación de esta institución pasó de manos de la Iglesia al Estado, jamás se secularizaron sus formas; por

16. Inés Argueta, "Familia 'natural' contra matrimonio igualitario: un fenómeno social que se repite", Cultura y representaciones sociales, año 11, $\mathrm{n} .^{\circ} 22$ (marzo 2017): 278-311.

17. Hernán Corral, "Sentido y alcance de la definición de matrimonio del artículo 102 del Código Civil, después de la introducción del divorcio vincular por la Ley 19.947, de 2004”, Revista Chilena de Derecho, vol. 36, n. ${ }^{\circ} 1$ (Santiago: 2009): 51-76.

18. Andrea Vizcaíno de la Torre, "La pugna por definir el matrimonio. Análisis del debate legislativo sobre el matrimonio igualitario en la Ciudad de México", Cultura y representaciones sociales, año 12, n. ${ }^{\circ} 24$ (marzo 2018): 339-66. 
tanto, continúa la necesidad de la condición de heterosexualidad para la procreación, es decir, la "naturalización" o "biologización". ${ }^{19}$

Si bien uno podría señalar al final que el Estado ecuatoriano es uno de carácter laico ${ }^{20}$ eso implicaría que este no podría asumir una posición religiosa. Por otro lado, desde la visión liberal se establece que este debería asumir una plena neutralidad sobre el matrimonio, es decir, que podría evitar estas controversias morales y religiosas, para dejarlo en el ámbito de la privacidad y el ejercicio de la autonomía de la voluntad de cada individuo, que no es más que: el argumento moral sofisticado.

\section{El ARgumento de LA LiberTAd}

Ahora bien, este argumento moral sofisticado sostendría que desde la noción de libertad -voluntarista- cualquier individuo debería tener la opción de escoger de forma libre si quiere o no acceder al matrimonio, sea homosexual o heterosexual, siempre y cuando no haga daño a los demás, dejando de lado su valoración moral. Es decir, la forma del argumento de libertad seria:

1. Las relaciones homosexuales son elección de cada persona.

2. El Estado es neutral en cuestiones morales.

3 El Estado no puede juzgar las relaciones homosexuales.

4. Las relaciones homosexuales no son cuestión del Estado.

Desde estas premisas, se evidencia que puede haber diferentes concepciones morales sobre las relaciones homosexuales, sin embargo, el Estado debe abstenerse de imponer una de estas, en el sentido del concepto matrimonio, lo que implica que no puede ser visto únicamente como la unión entre hombre y mujer, sino que debe dejar a las personas que elijan la relación que ellos consideran más pertinente para su vida privada. Con esto se pretendería una solución ecuánime que permita tanto a heterosexuales como a homosexuales casarse.

19. Ibíd.

20. Art. 1 CRE, Ecuador. "Constitución de la República del Ecuador" (Quito: Registro Oficial 449, 20 de octubre de 2008), que señala: Art. 1.- El Ecuador es un Estado constitucional de derechos y justicia, social, democrático, soberano, independiente, unitario, intercultural, plurinacional y laico. Se organiza en forma de república y se gobierna de manera descentralizada. La soberanía radica en el pueblo, cuya voluntad es el fundamento de la autoridad, y se ejerce a través de los órganos del poder público y de las formas de participación directa previstas en la Constitución. Los recursos naturales no renovables del territorio del Estado pertenecen a su patrimonio inalienable, irrenunciable e imprescriptible. 
Sin embargo, Michael Sandel no cree que esta es una auténtica solución al problema, porque evade la cuestión principal de la discusión que es si el Estado debe regular jurídicamente algunas formas de uniones sexuales con preferencia de otras. ${ }^{21}$ Por otro lado, el mismo Sandel nos dota de una tercera opción, que establecería que el Estado no regule ninguna relación de pareja, y que esto pase al ámbito exclusivamente de privados. Esta se trataría de "desoficializar" el matrimonio como cuestión del Estado que le dota de un concepto jurídico al mismo, sino que, como señala Michael Kinsley, que tanto las iglesias como cualquier otra institución jurídica, un casino, o cualquier asociación privadas pueda celebrar matrimonios. ${ }^{22}$

No obstante, aunque tentador y quizás relevante, esta opción se sostiene como impracticable. En conclusión, se tiene que volver a retrotraer la discusión a cuál es el concepto de matrimonio que el Estado y el ordenamiento jurídico deben reconocer, proteger, así como los tipos de familia.

Así, el matrimonio igualitario no puede resolverse simplemente sosteniendo, como lo hacen algunos liberales, que el Estado debe ser moralmente neutro, y que por tanto no debe entrar ni a juzgar la calidad moral de las relaciones homosexuales, sino que, justamente, se empiece a tratar desde donde habíamos empezado la discusión, en la tesis moral: ¿Cuáles son los fines -telos-del matrimonio?

\section{EL ARGUMENTO DE LOS FINES DEL MATRIMONIO}

La tesis de la procreación atada al matrimonio es claramente deficitaria para lograr definir a esta última; de la misma forma, la tesis de la libertad también es insuficiente para poder obtener una justificación moral. En cambio, desde el argumento moral ingenuo -sustantivo- se puede señalar que lo que se valora en el matrimonio convencional está presente también en el matrimonio igualitario, como, por ejemplo, el vivir juntos o en armonía, auxiliarse mutuamente.

De esta forma, es indispensable empezar a deliberar sobre valoración de las relaciones homosexuales y si estas cumplen con las finalidades de la institución jurídica y social del matrimonio. En este sentido, como ya se ha señalado, la procreación no es el único fin que tiene esta institución, sino que además están otros como el de unirse con el fin de vivir juntos y auxiliarse mutuamente. En tanto, el movimiento pro-matrimonio heterosexual no ha podido satisfacer que la principal finalidad de este es únicamente la procreación. No obstante, concordamos con esta posición en que

21. Michael Sandel, “Justicia. ¿Hacemos lo que debemos?” (Barcelona: De Bolsillo, 2013).

22. Ibíd. 
debemos empezar a discutir de manera frontal y sería los argumentos de tipo moral que le subyacen.

No podemos concordar con los liberales en señalar que la discusión de los valores morales no tiene cabida en un Estado laico, puesto que el mismo no debe preferir doctrina moral alguna; es imprescindible formular nuestros propios argumentos de índole moral que permitan enfrentar a quienes defienden la posición más conservadora -pro-matrimonio heterosexual.

Como acertadamente señala Sandel, si regresamos a Aristóteles, rivalizar sobre el propósito o razón -telos- de ser de una institución social sería igual que discutir sobre las virtudes que deben honrarse y recompensarse. ${ }^{23}$ Así, como ya se evidenciado en el caso del matrimonio, entre sus fines se encuentra el de vivir juntos y auxiliarse mutuamente. Estos propósitos están presentes tanto en las parejas heterosexuales como en las homosexuales. Partiendo de ahí, se concluye que las uniones homosexuales tienen el mismo valor moral de las heterosexuales.

En consecuencia, la tesis que esboza que el Estado debe permitir el matrimonio igualitario, por cuanto este debe ser neutro ante las preferencias sexuales de cada persona, no sería la adecuada, sino que valdría remplazarla por la de que el matrimonio igualitario debe ser reconocido legalmente porque las uniones homosexuales tienen el mismo valor moral de las heterosexuales, por los fines que estos comparten. No obstante, nos queda un último argumento que es de la igualdad y la diversidad, que puede dar cuenta de mejor forma del matrimonio y la familia desde una óptica de los derechos.

\section{El ARGUMENTO DE LA IGUALDAD Y LA DIVERSIDAD}

Como señala Pérez Royo, la Constitución es el resultado de la afirmación del principio de igualdad ${ }^{24}$ que rompe con la historia de la humanidad que, en buena parte, se fundó en la desigualdad de hecho y de derecho. Así, el poder político debe ser constituido y debe ser coherente con el principio de igualdad. ${ }^{25}$ Ahora bien, el principio de igualdad y no discriminación está reconocido en el derecho internacional, desde la finalización de la Segunda Guerra Mundial, en la Declaración Universal de los Dere-

23. Ibíd.

24. Javier Pérez Royo, Curso de Derecho Constitucional (Madrid: Marcial Pons, 2010).

25. Ibíd. 
chos Humanos, ${ }^{26}$ en el Pacto Internacional de los Derechos Civiles y Políticos, ${ }^{27}$ en el Convenio Europeo de Derechos Humanos ${ }^{28}$ y en la Convención sobre los Derechos del Niño: ${ }^{29}$ son cuerpos normativos a nivel internacional que garantizan este principio en cuanto al ejercicio de los derechos.

Además de estos instrumentos internacionales de derechos humanos, tenemos la Carta de la OEA, ${ }^{30}$ la Convención Americana de Derechos Humanos, ${ }^{31}$ la Convención de Belem do Para que también señala la cláusula de prohibición de discriminación; ${ }^{32}$ asimismo la Opinión Consultiva n. ${ }^{\circ} 4$ de la Corte IDH indica:

No habrá, pues, discriminación si una distinción de tratamiento está orientada legítimamente, es decir, si no conduce a situaciones contrarias a la justicia, a la razón o a

26. Art. 2.- Toda persona tiene todos los derechos y libertades proclamados en esta Declaración, sin distinción alguna de raza, color, sexo, idioma, religión, opinión política o de cualquier otra índole, origen nacional o social, posición económica, nacimiento o cualquier otra condición.

27. Art. 2 n. ${ }^{\circ}$ 1.- Cada uno de los Estados Partes en el presente Pacto se compromete a respetar y a garantizar a todos los individuos que se encuentren en su territorio y estén sujetos a su jurisdicción los derechos reconocidos en el presente Pacto, sin distinción alguna de raza, color, sexo, idioma, religión, opinión política o de otra índole, origen nacional o social, posición económica, nacimiento o cualquier otra condición social. Art. 26.- Todas las personas son iguales ante la ley y tienen derecho sin discriminación a igual protección de la ley. A este respecto, la ley prohibirá toda discriminación y garantizará a todas las personas protección igual y efectiva contra cualquier discriminación por motivos de raza, color, sexo, idioma, religión, opiniones políticas o de cualquier índole, origen nacional o social, posición económica, nacimiento o cualquier otra condición social.

28. Art. 14.- El goce de los derechos y libertades reconocidos en el presente Convenio ha de ser asegurado sin distinción alguna, especialmente por razones de sexo, raza, color, lengua, religión, opiniones políticas u otras, origen nacional o social, pertenencia a una minoría nacional, fortuna, nacimiento o cualquier otra situación.

29. Art. 2 n. ${ }^{\circ}$ 1.- Los Estados Partes respetarán los derechos enunciados en la presente Convención y asegurarán su aplicación a cada niño sujeto a su jurisdicción, sin distinción alguna, independientemente de la raza, el color, el sexo, el idioma, la religión, la opinión política o de otra índole, el origen nacional, étnico o social, la posición económica, los impedimentos físicos, el nacimiento o cualquier otra condición del niño, de sus padres o de sus representantes legales.

30. Art. 3 n. ${ }^{\circ}$ 1.- Los Estados americanos reafirman los siguientes principios: Los Estados americanos proclaman los derechos fundamentales de la persona humana sin hacer distinción de raza, nacionalidad, credo o sexo.

31. Art. $1 \mathrm{n} .^{\circ}$ 1.- Los Estados Partes en esta Convención se comprometen a respetar los derechos y libertades reconocidos en ella y a garantizar su libre y pleno ejercicio a toda persona que esté sujeta a su jurisdicción, sin discriminación alguna por motivos de raza, color, sexo, idioma, religión, opiniones políticas o de cualquier otra índole, origen nacional o social, posición económica, nacimiento o cualquier otra condición social.

Art. 24.- Todas las personas son iguales ante la ley. En consecuencia, tienen derecho, sin discriminación, a igual protección de la ley.

32. Art. 6.- El derecho de toda mujer a una vida libre de violencia incluye, entre otros:

a) el derecho de la mujer a ser libre de toda forma de discriminación, y

b) el derecho de la mujer a ser valorada y educada libre de patrones estereotipados de comportamiento y prácticas sociales y culturales basadas en conceptos de inferioridad o subordinación. 
la naturaleza de las cosas. De ahí que no pueda afirmarse que exista discriminación en toda diferencia de tratamiento del Estado frente al individuo, siempre que esa distinción parta de supuestos de hecho sustancialmente diferentes y que expresen de modo proporcionado una fundamentada conexión entre esas diferencias y los objetivos de la norma, los cuales no pueden apartarse de la justicia o de la razón, vale decir, no pueden perseguir fines arbitrarios, caprichosos, despóticos o que de alguna manera repugnen a la esencial unidad y dignidad de la naturaleza humana. ${ }^{33}$

En este sentido, la Corte IDH reconoce la existencia de la igualdad ante la ley, es decir la igualdad formal, y también establece que no todo trato jurídico diferente necesariamente es discriminatorio, ya que pueden existir desigualdades de facto que se traducen de forma legítima en desigualdades de iure. De la misma forma el Comité de Derechos Humanos de Naciones Unidas en 1989, dentro de su Observación General n. ${ }^{\circ} 18$ párrafo 7 , define la discriminación en los siguientes términos:

Debe entenderse referido a toda distinción, exclusión, restricción o preferencia que se basen en determinados motivos, como la raza, el color, el sexo, el idioma, la religión, la opinión política o de otra índole, el origen nacional o social, la posición económica, el nacimiento o cualquier otra condición social, y que tenga por objeto o por resultado anular o menoscabar el reconocimiento, goce o ejercicio, en condiciones de igualdad, de los derechos humanos y libertades fundamentales de todas las personas. ${ }^{34}$

En síntesis, el argumento de la igualdad, que jurídicamente está reconocido en el derecho internacional, implica la prohibición de discriminación, es decir, que cualquier distinción o exclusión que se base en categorías como raza, sexo, religión u otras que tengan como finalidad menoscabar el ejercicio de los derechos y libertades está prohibida jurídicamente. Si bien esto es claro, el argumento de la igualdad también implica que todos debemos tener obligatoriamente un trato igual dentro del Estado constitucional de derechos y justicia, y que cualquier distinción debe ser justificada con un mayor peso argumentativo. Como ya hemos dejado en claro en los otros apartados, el concepto de matrimonio y el de familia se han ido refinando y más bien podemos hablar de concepciones. Así, instituciones jurídicas y políticas como el voto o la ciudadanía se han ido reformando y ampliando a través de la historia constitucional; por ende, los conceptos varían y no son inmutables.

Por otro lado, se ataca al argumento igualitario señalando que no se permite hacer distinciones entre iguales. Es decir que no se puede tratar igual a los que no son

33. Párrafo 57.

34. ONU Comité de Derechos Humanos, CCPR Observación General n. ${ }^{\circ}$ 18, No Discriminación (10 de noviembre de 1989, párr. 7). 
iguales: el derecho discrimina cuándo trata de modo desigual a los iguales, pero no cuándo trata diferente a los diferentes. Pero este argumento deficitario de la igualdad implicaría que todos somos iguales, cuando esto no es así, porque también existen diferencias, es decir, Pedro y Pepita son iguales como seres humanos, pero uno es hombre y la otra mujer, el uno puede ser rico y ella pobre. Entonces, ¿qué implicaría que el derecho debe tratar como iguales a los iguales, y diferente a los diferentes? Desde esa perspectiva, se debe analizar la relevancia de las igualdades, es decir, que buenas razones se deben dar para justificar si una igualdad es relevante para la distribución de un derecho y su alcance.

Por tanto, de nuevo regresamos a si es de relevancia moral diferenciar a seres humanos por su preferencia sexual. En sentido estricto, debemos reflexionar si al momento de querer acceder al matrimonio las preferencias sexuales son o no relevantes para tener o no esa posibilidad jurídica. Y, además, que esa relevancia implique que el Estado deba reaccionar negativamente a esa posibilidad, es decir, generar un trato diferente y peor que el que tienen las personas que quieren casarse entre personas de diferente sexo, cuando claramente en varios Estados se han garantizado las acciones positivas justamente para tratar de compensar el trato discriminatorio y la desigualdad de cientos de años del que fueron objeto grupos como las mujeres.

En este sentido, lo pertinente sería considerar que todos -seamos hombres, mujeres, blancos, mestizos, negros, católicos, ateos, heterosexuales, homosexuales- somos sujetos iguales. Y lo razonable sería más bien generar las compensaciones hacia quienes históricamente han sido excluidos y maltratados con el fin de superar las situaciones injustas de las que fueron objeto. Finalmente, bajo esa idea se dice que, en una sociedad de derechos, que establece la igualdad como principio, como lo señala la Constitución ecuatoriana, se determina que el Estado debe garantizar los beneficios a los que se asigna a otros, y no puede privar de los mismos a otros, sin una razón extremadamente fuerte. Lo que implica que, de hacerlo, generaría discriminación al despojarle de ese derecho. Incluso si esa privación se sustenta en la decisión de la mayoría por sobre las minorías, lo cual no podría ser una decisión aceptable al estar negando derechos dentro de una democracia constitucional que privilegia el coto vedado: los derechos fundamentales.

\section{CONCLUSIONES}

Evidentemente las reflexiones que se han sostenido no pretenden ser exhaustivas sobre lo que implica el matrimonio y su concepto a la luz de la Opinión Consultiva 24/17, pero han intentado recoger algunos de los elementos más importantes que son la médula del debate jurídico y moral. 
En cuanto a la tesis interpretativa hemos podido observar que varias de las normas que pueden ser obtenidas del proceso de atribución de significado del texto constitucional, serían inconcluyentes en cuanto a que no establecerían una prohibición explícita del matrimonio entre personas del mismo sexo. Por ende, esos límites interpretativos, en especial con el uso de la interpretación literal, no son garantía suficiente de una certeza jurídica sobre el matrimonio y su concepto.

En cuanto a la tesis moral se evidencia que el argumento de la procreación es igualmente exiguo para poder sustentar que el matrimonio heterosexual se erige sobre el mismo, así como el argumento de libertad es insuficiente al señalar que el Estado debe mantenerse al margen de las valoraciones morales que las instituciones jurídicas o sociales tengan.

En cuanto a la igualdad, critiqué algunos de los argumentos que se emplean durante los debates en torno a la propuesta del matrimonio civil igualitario. Me interesó defender este principio, ya que, conforme a dicho argumento, el Estado tiene el deber de tratar a todos los miembros de la sociedad como iguales. Sostengo que aquellos que defienden la imposibilidad de acceso al matrimonio entre personas del mismo sexo, deberían ser capaces de argumentar por qué esa distinción es jurídicamente relevante, lo cual no se ha demostrado.

Al final se pudo demostrar que solo si acudimos a una interpretación literal y sistemática de la Constitución, se puede dar una mayor consistencia y coherencia al ordenamiento jurídico en relación al concepto de matrimonio. Asimismo, solo si asumimos que es necesario entrar a discutir y dar valoraciones morales sobre los fines del matrimonio; pero el principal argumento es el de la igualdad que permite llegar a una justificación más adecuada del matrimonio igualitario.

En fin, la posición de la valoración moral equitativa de los fines del matrimonio y su proceso de deliberación es trascendente; para algunos ya es caduca, pero para quienes no pueden acceder implica una restricción al ejercicio sus derechos.

\section{BIBLIOGRAFÍA}

Argueta, Inés. "Familia 'natural' contra matrimonio igualitario: un fenómeno social que se repite”. Cultura y representaciones sociales. Año 11, n. 22 (marzo 2017): 278-311.

Ávila, Ramiro. Los derechos y sus garantías: ensayos críticos. Quito: Corte Constitucional para el Período de Transición / CEDEC, 2012.

Comité de Derechos Humanos de Naciones Unidas. “Observación General n. o 18”. Ginebra, 10 de noviembre de 1989.

“Convención de Belém do Pará”. Belém do Pará, 9 de junio de 1994. 
Corral, Hernán. "Sentido y alcance de la definición de matrimonio del artículo 102 del Código Civil, después de la introducción del divorcio vincular por la Ley 19.947, de 2004". Revista Chilena de Derecho. Vol. 36, n. ${ }^{\circ} 1$ (2009): 51-76.

Corte Interamericana de Derechos Humanos. “Opinión Consultiva OC-4/84”, 19 de enero de 1984.

—. “Opinión Consultiva 24/17”, 24 de noviembre de 2017.

Ecuador. Código Civil. Registro Oficial 46, 24 de junio de 2005.

-. Constitución de la República del Ecuador. Registro Oficial 449, 20 de octubre de 2008.

Europa, Consejo de. "Convenio Europeo de Derechos Humanos". Roma, 4 de noviembre de 1950.

Guastini, Riccardo. Teoría e ideología de la interpretación constitucional. Madrid: Trotta, 2008.

—. La sintaxis del derecho. Madrid: Marcial Pons, 2016.

Hart, Herbert L. El concepto del Derecho. Buenos Aires: Abeledo Perrot, 2008.

IX Conferencia Internacional Americana. "Carta de la OEA". Bogotá, 30 de abril de 1948.

OEA. "Convención Americana sobre Derechos Humanos". San José, 22 de noviembre de 1969.

ONU. “La Declaración Universal de los Derechos Humanos”. París, 10 de diciembre de 1948.

—. "Convención sobre los Derechos del Niño". Nueva York, 20 de noviembre de 1989.

"Pacto Internacional de los Derechos Civiles y Políticos". Nueva York, 16 de diciembre de 1966.

Pérez Royo, Javier. Curso de Derecho Constitucional. Madrid: Marcial Pons, 2010.

Sandel, Michael. Filosofía pública. Ensayos sobre moral en política. Barcelona: Marbot, 2008.

—. Justicia. ¿Hacemos lo que debemos? Barcelona: De Bolsillo, 2013.

Solano, Vicente. "Controversias interpretativas sobre la regulación en la Constitución ecuatoriana de la interpretación constitucional". En Vicente Solano y Marcelo Aguilera, Hitos de la Constitución Ecuatoriana, 43-60. Cuenca: EDUNICA, 2018.

Vizcaíno de la Torre, Andrea Alicia. "La pugna por definir el matrimonio. Análisis del debate legislativo sobre el matrimonio igualitario en la Ciudad de México". Cultura y representaciones sociales. Año 12, n. 24 (marzo 2018): 339-66. 